\title{
Spectrum and Antimicrobial Susceptibility Pattern of Micro-Organisms Associated With Neonatal Sepsis in a Hospital in Karachi, Pakistan \\ Mehmood Shaikh ${ }^{1}$, Muhammad Hanif ${ }^{1}$, Rafia Gul ${ }^{2}$, Wajid Hussain ${ }^{3}$, Hemandas Hemandas ${ }^{4}$, Ashraf Memon ${ }^{5}$
}

\begin{abstract}
1. Neonatology, Jinnah Sindh Medical University, Karachi, PAK 2. Neonatology, Fatima Memorial Hospital, Lahore, PAK 3. Paediatrics, Jinnah Sindh Medical University, Karachi, PAK 4. Paediatrics, Peterborough City Hospital, Peterborough,
\end{abstract} GBR 5. Pathology, Kharadar General Hospital, Karachi, PAK

Corresponding author: Hemandas Hemandas, drhemandas@gmail.com

\section{Abstract}

\section{Background}

Neonatal sepsis is one of the most common causes of neonatal mortality and morbidity, particularly in developing countries. Its causative bacteria and their respective sensitivity patterns are different in each hospital and region. The objective of this study was to determine the causative bacteria and their antibiotics sensitivity patterns at the neonatal unit.

\section{Methods}

This prospective study was carried out at the Neonatology Unit of Kharadar General Hospital (KGH) from January 2017 to Jun 2019. A total of 162 neonates with suspected sepsis and positive blood cultures were included in the study. Blood culture was done by standard microbiological techniques (BACTEC Method). Continuous data were presented as mean and standard deviation, while categorical data were presented in frequency and percentages.

\section{Result}

Out of a total of 162 neonates with blood culture positive neonatal sepsis, males were 106 (65.4\%). Grampositive and Gram-negative bacteria were found with a frequency of $83(51.5 \%)$ and 79 (48.5\%), respectively. Staphylococcus aureus and Pseudomonas were the commonest isolates in $50.5 \%$ and $25.7 \%$ of cases, respectively. The Gram-positive organism was mostly sensitive to amikacin and vancomycin whereas the Gram-negative was mostly sensitive to amikacin, imipenem, meropenem, and ciprofloxacin.

Review began 09/24/2020 Review ended 10/04/2020 Published 10/13/2020

\section{Copyright 2020} Shaikh et al. This is an open access article distributed under the terms of the Creative Commons Attribution License CC-BY 4.0., which permits unrestricted use, distribution, and reproduction in any medium, provided the original author and source are credited.

\section{Conclusion}

Staphylococcus aureus was the most common bacteria isolated. For the sepsis, the causative bacteria and antibiotics sensitivity pattern changes over a period of time. Continued surveillance is required to help reduce morbidity and mortality through developing institution-based guidelines.

Categories: Pediatrics, Infectious Disease

Keywords: neonates, sepsis, causative bacteria, antimicrobial sensitivity

\section{Introduction}

Neonatal sepsis is defined as bacteremia and clinical symptoms caused by micro-organisms and their toxic products [1]. It can be either early-onset sepsis which usually presents within the first 72 hours of life or late-onset sepsis, which presents at 72 hours after birth up to 28 days of life [2].

The incidence of neonatal sepsis varies from 7.1 to 38 per 1000 live births in Asia, 6.5 to 23 per 1000 live births in Africa, 3.5 to 8.9 per 1000 live births in South America, and six to nine per 1000 live births in the United States [3]. Sepsis is a significant cause of morbidity and mortality in newborns where it contributes up to $13 \%-15 \%$ of deaths in developed countries, $30 \%-50 \%$ deaths in developing countries, and $28 \%$ deaths in Pakistan [4-6]. Clinical manifestation of neonatal sepsis is diverse which includes the maternal feeling of unwell baby, lethargy, vomiting, variability in temperature, respiratory rate and heart rate, jaundice, hepatomegaly, cyanosis, apnea, and abdominal distention [7]. In developing countries, Gram-negative organisms like Escherichia coli and Klebsiella have been found to be the leading cause of neonatal infections followed by Gram-positive organisms including Staphylococcus aureus, Group B Streptococcus (GBS), and Staphylococcus epidermidis [8-10]. In contrary to this, in developed countries, Group B Streptococcus, followed by Escherichia coli, Staphylococcus aureus, Coagulase-negative staphylococcus (CoNS), Listeria monocytogenes, Klebsiella spp., Enterococcus spp., and Pseudomonas aeruginosa are causative organisms of neonatal sepsis [11-13].

Neonatal sepsis is one of the commonest reasons for admission in the neonatology unit. As culture and sensitivity pattern varies at different places and duration, the WHO recommends determination of local culture and sensitivity pattern for starting antibiotics. In our setup, we lack the susceptibility spectrum of microorganisms responsible for neonatal sepsis, which is essential to make a choice of appropriate 


\section{Cureus}

antibiotics in affected neonates. The results of this study will not only help to determine the causative organisms of sepsis in our population but also promote the judicious use of empirical antibiotics. This will result in shorter hospital stay of neonates, reduction in adverse effects of drugs, and cost-effective management of sepsis.

\section{Materials And Methods}

This prospective cross-sectional study was conducted from 1st January 2017 to 30th June 2019 in the neonatology unit, Kharadar General Hospital (KGH), Karachi. The study was initiated after obtaining permission from the IRB. Informed consent was obtained from the parents or guardians. A total of 162 neonates of either gender admitted in the neonatal unit through paediatric OPD/emergency room who presented with sepsis and their blood cultures were found to be positive were included in the study. Detailed history and examination were carried out in all patients presenting with sepsis. The neonates with incomplete data on proforma were excluded from the study. About $5 \mathrm{cc}$ (minimum $1 \mathrm{cc}$ ) of venous blood samples were withdrawn and, directly injected into BACTEC ${ }^{\circledR}$ PEDS Plus (Becton Dickinson, Towson, MD) culture media bottle after using aseptic technique. The sample was transported to the laboratory for processing blood cultures. In the microbiology section of KGH lab, the BACTEC bottle was loaded in BACTEC 9050 automated blood culture instrument, based on fluorescent technology with continuous, unattended testing of cultures. When positive vials were identified, the lab technologist took out a specific bottle from the BACTEC instrument for gram staining as well as subculturing on specific media by inoculating the culture broth on blood, chocolate and MacConkey agar plates. These plates were then incubated in an incubator at $37^{\circ} \mathrm{C}$ in chocolate plate also under a candle jar for 24 hours. On the next day, the culture plate was read for their colony characteristic and the further biochemical test was run for the identification of specific microorganisms, as well as antibiotic susceptibility test was performed by disk diffusion technique. As per protocol, the negative sample remained the instrument for five days and then the report declared as negative. Results were analyzed using SPSS version 20 (IBM Corp., Armonk, NY). The qualitative variable was presented as mean and standard deviation, while quantitative variables presented in frequency and percentages. A Chi-square test was used to compare the variables. P-value $\leqslant 0.05$ was considered statistically significant.

\section{Results}

Between January 2015 and June 2017, 1960 neonates were admitted to the neonatology unit with a diagnosis of sepsis or developed sepsis during the hospital stay. A total of 162 out of 1960 neonates had a positive blood culture. A total of 106 (65.4\%) were male and 56 (34.5\%) were female babies making a male: female ratio 1.89:1. The mean age of admission was $140 \pm 131$ hours. Mean birth weight was $2.44+0.71 \mathrm{~kg}(0.8-4.5$ $\mathrm{kg})$. Gram-positive bacteria were more frequent than Gram-negative bacteria with a frequency of 83 (51.5\%) and 79 (48.5\%), respectively. Among Gram-positive isolates, Staphylococcus aureus (50.1\%) was the commonest organism isolated followed by Enterococci spp. (1\%), while in Gram-negative isolates, Pseudomonas spp. was most common (25.7\%) followed by Klebsiella (10.5\%) (Figure 1).

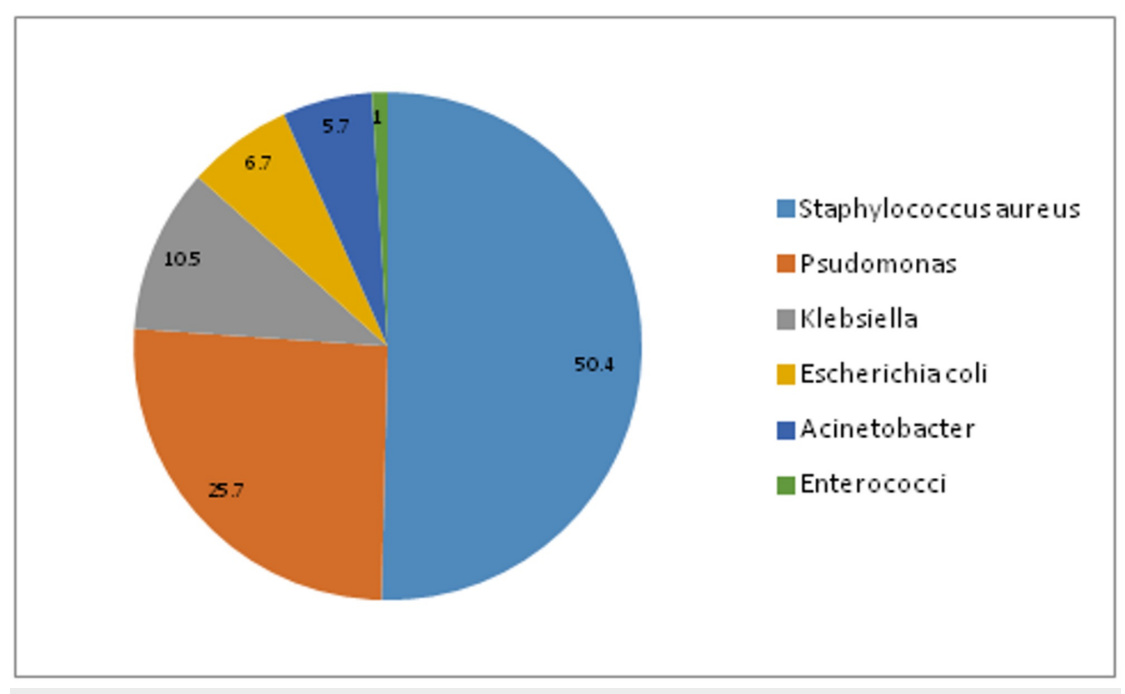

FIGURE 1: Distribution of micro-organisms involved in neonatal sepsis.

The bacteria responsible for the sepsis showed a variable pattern of antibiotics sensitivity. The results of antibiotic sensitivity, the pattern of Gram-positive bacteria were as shown in Table 1. 


\section{Cureus}

\begin{tabular}{|c|c|c|}
\hline Antibiotics & Staphylococcus aureus & Enterococci spp. \\
\hline Amikacin & $85 \%$ & $100 \%$ \\
\hline Amoxicillin/clavulanate & $47.1 \%$ & $0 \%$ \\
\hline Cefotaxime & $16.9 \%$ & $100 \%$ \\
\hline Ceftazidime & $11.3 \%$ & $0 \%$ \\
\hline Ceftriaxone & $26.4 \%$ & $100 \%$ \\
\hline Chioramphenicol & $68 \%$ & $0 \%$ \\
\hline Ciprofloxacin & $16.9 \%$ & $100 \%$ \\
\hline Clindamycin & $66 \%$ & $100 \%$ \\
\hline Cloxacillin & $28.3 \%$ & $100 \%$ \\
\hline Enoxacin & $47.1 \%$ & $100 \%$ \\
\hline Gentamicin & $5.6 \%$ & $0 \%$ \\
\hline Lincomycin & $79.24 \%$ & $100 \%$ \\
\hline Methıcillin & $15 \%$ & $0 \%$ \\
\hline Ofioxacin & $32 \%$ & $100 \%$ \\
\hline Oxacillin & $30.1 \%$ & $100 \%$ \\
\hline Vancomycin & $88.67 \%$ & $0 \%$ \\
\hline
\end{tabular}

TABLE 1: Antibiotic sensitivity pattern of Gram-positive bacteria.

The results of antibiotic sensitivity, the pattern of Gram-negative bacteria were as shown in Table 2 .

\begin{tabular}{|c|c|c|c|c|}
\hline Antibiotics & Pseudomonas spp. & Klebsiella spp. & Escherichia coli & Acinetobacter \\
\hline Amikacin & $85 \%$ & $82 \%$ & $100 \%$ & $66.6 \%$ \\
\hline Amoxicillin/Clavulanate & $7.4 \%$ & $36.36 \%$ & $57.1 \%$ & $66.6 \%$ \\
\hline Cefotaxime & $0 \%$ & $27.27 \%$ & $14.2 \%$ & $0 \%$ \\
\hline Ceftazidime & $29.6 \%$ & $9 \%$ & $0 \%$ & $0 \%$ \\
\hline Ceftriaxone & $26 \%$ & $54.54 \%$ & $14.2 \%$ & $33.3 \%$ \\
\hline Chloramphenicol & $14.8 \%$ & $18.1 \%$ & $0 \%$ & $16.6 \%$ \\
\hline Ciprofloxacin & $77.7 \%$ & $63.6 \%$ & $57.1 \%$ & $16.6 \%$ \\
\hline Clindamycin & $7.4 \%$ & $9 \%$ & $0 \%$ & $0 \%$ \\
\hline Gentamicin & $32 \%$ & $63 \%$ & $71.4 \%$ & $66.66 \%$ \\
\hline Imipenem & $77.7 \%$ & $100 \%$ & $100 \%$ & $33.3 \%$ \\
\hline Meropenem & $74 \%$ & $100 \%$ & $100 \%$ & $33.3 \%$ \\
\hline Ofloxacin & $44.4 \%$ & $9 \%$ & $14.2 \%$ & $0 \%$ \\
\hline Oxacillin & $3.7 \%$ & $9 \%$ & $0 \%$ & $0 \%$ \\
\hline Piperacillin & $61.5 \%$ & $0 \%$ & $0 \%$ & $16.6 \%$ \\
\hline Tobramycin & $70.3 \%$ & $36.36 \%$ & $42.8 \%$ & $16.6 \%$ \\
\hline Vancomycin & $3.7 \%$ & $9 \%$ & $0 \%$ & $0 \%$ \\
\hline
\end{tabular}

TABLE 2: Antibiotic sensitivity pattern of Gram-negative bacteria. 


\section{Discussion}

Neonatal sepsis is considered to be an important cause of neonatal morbidity and mortality [14]. Developing countries share $99 \%$ of the estimated 4 million neonatal deaths [15]. Out of 4 million one-fourth die due to neonatal sepsis [16-17]. The timely diagnosis of neonatal sepsis plays an important role in determining the outcome of the babies. Blood culture is a gold standard test for sepsis [18].

Hubacek et al. have shown that the polymorphism in genes for lysosomal binding protein is responsible for the immunological difference between males and females [19]. Marriott et al. observed that cell surface receptors like TLR 4 trigger a different response in males than females in terms of inflammatory cytokines and acute-phase reactants thus making males more prone to sepsis [20]. Our study was conducted on 162 neonates with confirmed sepsis on blood culture. Male babies were 106 (65.4\%) and female babies were 56 (34.5\%) with a ratio of 1.89 to 1 , which is consistent with several studies [14, 21-22].

In the present study, however, $54.6 \%$ of isolates were Gram-positive bacteria while Gram-negative bacteria accounted for $45.4 \%$ of cases of neonatal septicemia. The results are consistent with other studies conducted by Draz et al. and Karlowicz et al. [17, 23]. There was a similarity in the findings in studies done by Muhammad et al., Movahedian et al., Awoniyi et al., Waseem et al., Shrestha et al., and Kayange et al.; they also found Gram-negative as the main organisms responsible for neonatal sepsis [14, 24-28]. The difference in organism patterns is because of the inclusion of hospital-acquired sepsis in our study which was not included in other studies.

Staphylococcus aureus is the most commonly isolated organism responsible for neonatal sepsis in our study. Similar results have been shown by Draz et al., Shaw et al., Mhada et al., and Najeeb et al. [17, 21, 29,30]. The other Gram-positive organisms to be isolated were Enterococci. A similar pattern of the predominance of Gram-positive organisms has been shown in studies conducted by Shrestha et al. [27]. In these studies, hospital-acquired sepsis was included.

Pseudomonas was the most common Gram-negative organism. These results are consistent with Awoniyi et al. [25]. In contrary to this, Shrestha et al. found Klebsiella pneumonia the most common Gram-negative organism [27]. Muhammad et al. and Najeeb et al. described Klebsiella in 10\% of the cases [14, 30]. These findings are nearly the same as our study. Shaw et al. and Waseem et al. isolated Klebsiella as the second most commonly isolated bacteria, i.e., in $18.32 \%$ and $30 \%$ of cases, respectively $[21,26]$.

Staphylococcus aureus was most sensitive to amikacin and vancomycin as $85 \%$ and $88.67 \%$, respectively. Similar results were also observed in the studies done by Shaw et al. and Najeeb et al. [21,30].

Regarding the sensitivity pattern of Pseudomonas spp., following drugs showed sensitivity in decreasing pattern as amikacin, imipenem, ciprofloxacin, meropenem, and piperacillin. A study conducted by Awoniyi et al. found Pseudomonas spp. was the most sensitive to amikacin [25]. These results coincide with our study. Pseudomonas spp. sepsis was sensitive to imipenem in $77.7 \%$ in our study which is consistent with a study done by Shrestha et al. [27]. The study performed by Shrestha et al. found that Pseudomonas showed sensitivity to ciprofloxacin (77\%) which is consistent with our result [27].

Kayange et al. found Klebsiella was highly sensitive to meropenem which coincides with the results of our study [28]. In a study conducted by Najeeb et al., 93\% of Klebsiella was sensitive to imipenem, $73 \%$ is sensitive to amikacin and $74 \%$ to ciprofloxin [30]. These results are in conformity with our study.

Amikacin, imipenem, meropenem, and ciprofloxacin showed a high sensitivity of $100 \%, 100 \%, 100 \%$, and $57 \%$ in the case of E. coli. The study by Muhammad et al. found almost similar sensitivity pattern [14].

\section{Conclusions}

Staphylococcus aureus and Pseudomonas are the most common organisms causing neonatal sepsis. Grampositive bacteria have sensitivity to vancomycin and amikacin, while Gram-negative bacteria have sensitivity to amikacin, imipenem, meropenem, and ciprofloxacin. In our country, common pathogens responsible for neonatal sepsis change over the period of time and from region to region. Improved and revised local data on the pattern of causative bacteria and antibiotics sensitivity patterns are required to help reduce morbidity and mortality through the development of institution-based guidelines.

\section{Additional Information \\ Disclosures}

Human subjects: All authors have confirmed that this study did not involve human participants or tissue. Animal subjects: All authors have confirmed that this study did not involve animal subjects or tissue. Conflicts of interest: In compliance with the ICMJE uniform disclosure form, all authors declare the following: Payment/services info: All authors have declared that no financial support was received from any organization for the submitted work. Financial relationships: All authors have declared that they have no financial relationships at present or within the previous three years with any organizations that might have an interest in the submitted work. Other relationships: All authors have declared that there are no other relationships or activities that could appear to have influenced the submitted work.

\section{References}


1. Waheed M, Laeeq A, Maqbool S: The etiology of neonatal sepsis and patterns of antibiotic resistance . J Coll Physicians Surg Pak. 2003, 13:449-452.

2. Chelliah A, Thyagarajan R, Katragadda R, Leela KV, Babu RN: Isolation of MRSA, ESBL and Amp- $\beta$ lactamases from neonatal sepsis at a tertiary care hospital. J Clin Diagn Res. 2014, 8:24-27. $10.7860 / \mathrm{jcdr} / 2014 / 8597.4512$

3. Vergnano S, Sharland M, Kazembe P, Mwansambo C, Heath PT: Neonatal sepsis: an international perspective. Arch Dis Child Fetal Neonatal Ed. 2005, 90:220-224. 10.1136/adc.2002.022863

4. Committing to child survival: a promise renewed - Progress report 2015 . (2020). Accessed: October 08, 2020: https://www.unicef.org/publications/index_83078.html\#: :text=Committing\%20to\%20Child\%20Survival\%3A\%20A\%20Promise\%

5. World Health Organization. World health statistics 2015. (2015). Accessed: October 08, 2020: http://www.who.int/gho/publications/world_health_statistics/2015/en/.

6. Khan A, Kinney M, Hazir T, et al.: Newborn survival in Pakistan: a decade of change and future implications . Health Policy Planning. 2012, 27:72-87. 10.1093/heapol/czs047

7. Palazzi DL, Klein JO, Baker CJ: Bacterial sepsis and meningitis. Infectious Diseases of the Fetus and Newborn Infant. Elsevier/Saunders, Philadelphia; 2010. 222. 10.1016/B0-72-160537-0/50008-6

8. Zaidi AKM, Huskins WC, Thaver D, Bhutta ZA, Abbas Z, Goldmann DA: Hospital-acquired neonatal infections in developing countries. Lancet. 2005, 365:1175-1188. 10.1016/S0140-6736(05)71881-X

9. Zaidi AKM, Thaver D, Ali SA, Khan TA: Pathogens associated with sepsis in newborns and young infants in developing countries. Pediatr Infect Dis J. 2009, 28:10-18. 10.1097/INF.0b013e3181958769

10. Downie L, Armiento R, Subhi R, Kelly J, Clifford V, Duke T: Community-acquired neonatal and infant sepsis in developing countries: efficacy of WHO's currently recommended antibiotics - systematic review and meta-analysis. Arch Dis Child. 2013, 98:146-154. 10.1136/archdischild-2012-302033

11. Stoll BJ, Hansen N, Fanaroff AA, et al.: Late-onset sepsis in very low birth weight neonates: the experience of the NICHD Neonatal Research Network. Pediatrics. 2002, 110:285-291. 10.1542/peds.110.2.285

12. Vergnano S, Menson E, Kennea N, et al.: Neonatal infections in England: the NeonIN surveillance network . Arch Dis Child Fetal Neonatal Ed. 2011, 96:9-14. 10.1136/adc.2009.178798

13. Stoll BJ, Hansen NI, Sánchez PJ, et al.: Early onset neonatal sepsis: the burden of group B Streptococcal and E. coli disease continues. Pediatrics. 2011, 127:817-826. 10.1542/peds.2010-2217

14. Muhammad Z, Ahmed A, Hayat U, Wazir MS, Rafiyatullah, Waqas H: Neonatal sepsis: causative bacteria and their resistance to antibiotics. J Ayub Med Coll Abbottabad. 2010, 22:33-36.

15. Thaver D, Zaidi AK: Burden of neonatal infections in developing countries: a review of evidence from community-based studies. Pediatr Infect Dis J. 2009, 28:3-9. 10.1097/INF.0b013e3181958755

16. Black RE, Cousens S, Johnson HL, et al.: Global, regional, and national causes of child mortality in 2008: a systematic analysis. Lancet. 2010, 375:1969-1987. 10.1016/S0140-6736(10)60549-1

17. Draz NI, Taha SE, Shady NMA, Ghany YSA: Comparison of broad range 16S rDNA PCR to conventional blood culture for diagnosis of sepsis in the newborn. Egyptian J Med Human Genetics. 2013, 14:403-411.

18. Gerdes JS: Clinicopathologic approach to the diagnosis of sepsis. Clin Perinatol. 1991, 18:361-381. 10.1016/S0095-5108(18)30528-1

19. Hubacek JA, Stüber F, Fröhlich D, et al.: Gene variants of the bactericidal/permeability increasing protein and lipopolysaccharide binding protein in sepsis patients: gender-specific genetic predisposition to sepsis. Crit Care Medicine. 2001, 29:557-561. 10.1097/00003246-200103000-00015

20. Marriott I, Bost KL, Huet-Hudson YM: Sexual dimorphism in expression of receptors for bacterial lipopolysaccharides in murine macrophages: a possible mechanism for gender-based differences in endotoxic shock susceptibility. J Reprod Immunol. 2006, 71:12-27. 10.1016/j.jri.2006.01.004

21. Shaw CK, Shaw $P$, Thapalial A: Neonatal sepsis bacterial isolates and antibiotic susceptibility patterns at a NICU in a tertiary care hospital in Western Nepal: a retrospective analysis. Kathmandu Uni Med J. 2007, 5:153-160.

22. Sheikh AN, Sajjad A, Hanif S: Neonatal sepsis: an evaluation of bacteriological spectrum, antibiotic susceptibilities and prognostic predictors at Civil Hospital, Karachi. Pak Pediatr J. 2014, 38:143-155.

23. Karlowicz MG, Buescher ES, Surka AE: Fulminant late-onset sepsis in a neonatal intensive care unit, 19881997, and the impact of avoiding empiric vancomycin therapy. J Pediatr. 2000, 106:1387-1390. 10.1542/peds.106.6.1387

24. Movahedian AH, Moniri R, Mosayebi Z: Bacterial culture of neonatal sepsis. Iranian J Publ Health. 2006, 35:84-89.

25. Awoniyi DO, Udo SJ, Oguntibeju OO: An epidemiological survey of neonatal sepsis in a hospital in Western Nigeria. Afr J Microbiol Res. 2009, 3:385-389.

26. Waseem R, Khan M, Izhar TS: Neonatal sepsis. Professional Med J. 2005, 12:451-456.

27. Shrestha S, Shrestha NC, Singh SD, Shrestha RPB, Kayestha S, Shrestha M, Thakur NK: Bacterial isolates and its antibiotic susceptibility pattern in NICU. Kathmandu Univ Med J. 2014, 11:66-70. 10.3126/kumj.v11i1.11030

28. Kayange N, Kamugisha E, Mwizamholya DL, Jeremiah S, Mshana SE: Predictors of positive blood culture and deaths among neonates with suspected neonatal sepsis in a tertiary hospital, Mwanza-Tanzania. BMC Pediatr. 2010, 10:39. 10.1186/1471-2431-10-39

29. Mhada TV, Fredrick F, Matee MI, Massawe A: Neonatal sepsis at Muhimbili National Hospital, Dar es Salaam, Tanzania; aetiology, antimicrobial sensitivity pattern and clinical outcome. BMC Public Health. 2012, 12:904. 10.1186/1471-2458-12-904

30. Najeeb S, Gillani S, Rizvi SK, Ullah R, Rehman AU: Causative bacteria and antibiotic resistance in neonatal sepsis. J Ayub Med Coll Abbottabad. 2012, 24:131-134. 